\title{
A PSICANÁLISE É UMA CIÊNCIA E O DISCURSO ANALÍTICO É UMA PRÁXIS?
}

Tania Coelho dos Santos

Tania Coelho dos Santos

Psicanalista

membro da

École de la Cause

Freudienne e da

Associação Mundial

de Psicanálise,

professora associada

IV do PPGTP/

UFRJ, bolsista

de Produtividade

Científica do $\mathrm{CNPq}$

1C., editora de

aSEPHallus, Revista de

Orientação Lacaniana

RESUMO: Proponho neste artigo que a psicanálise no sentido absoluto insere-se no campo da ciência. Com a topologia, os matemas, as fórmulas da sexuação e os nós borromeanos, Lacan insistiu em separar as estruturas do sentido. Faço uma distinção entre ciência e práxis, admitindo que a psicanálise se divide entre uma e outra. Entretanto, se a psicanálise no sentido absoluto é uma experiência que conduz a uma existência expurgada de sentido, tal distinção merece ser reexaminada.

Palavras-chave: Psicanálise, ciência, práxis, estrutura, sentido.

ABSTRACT: Is psychoanalysis a science and the analytical speech a praxis? I propose in this article that psychoanalysis is, in its absolute sense, within the field of science, since with topology, mathemes, formulas of sexualization and borromean knots, Lacan insisted on separating these structures of the meaning. I make a distinction between science and praxis, admitting that psychoanalysis is divided between one and other. However, if psychoanalysis is - in the absolute sense - an experience that leads to a meaningless existence, we better reexamine this distinction.

Keywords: Psychoanalysis, science, praxis, structure, meaning. 


\section{CIÊNCIA E PRÁXIS: LACAN VERSUS FREUD?}

Parto da distinção entre ciência e práxis, admitindo que a psicanálise se divide entre uma e outra. Adoto como orientação a definição de Miller acerca da psicanálise no sentido absoluto: uma experiência que conduz a uma existência expurgada de sentido. Recordo que, de acordo com Lacan, o nascimento da ciência é "uma mutação decisiva que, por intermédio da física, fundou a ciência no sentido moderno, sentido que se postula como absoluto” (1998, p.869). Miller (2010, p.57), ao se referir à “experiência psicanalítica no sentido absoluto”, emprega a mesma expressão que Lacan quando se referiu "à Ciência”. Cabe esclarecer que o existente, ao qual ele se refere, é Um-corpo marcado pelo significante. Ideia, aliás, que é exatamente o contrário de nossa prática, pois, se o existente é um significante solitário, o trabalho analítico contraria o autismo da solidão do significante. Existiria, por conseguinte, uma antinomia interna entre o horizonte da psicanálise - o real na medida em que exclui todo sentido e que se escreve por meio da disjunção S1//S2 — e a prática, que opera por meio da conexão S1-S2, engendrada pela interpretação. Proponho aqui que a psicanálise no sentido absoluto insere-se no campo da ciência, à medida que, com a topologia, os matemas, as fórmulas da sexuação e os nós borromeanos, Lacan insistiu em separar as estruturas do sentido:

"Que a ciência repouse, não como se diz sobre a quantidade, mas sobre o número, a função e a topologia é o que não deixa dúvida. Um discurso que se chama ciência encontrou o meio de se construir atrás do muro. Só que acredito dever nitidamente formular, e nisso creio estar de acordo com tudo que há de mais sério na construção científica, que é estritamente impossível dar ao que quer que se articule em termos algébricos ou topológicos, a sombra de um sentido." (LACAN, 1971-72b, aula de 03/02/1972, p.68-69)

Podemos afirmar que, ao final de sua análise, um ser falante aproxima-se de reconhecer o sem sentido de sua existência. Isto é a mesma coisa que circunscrever o significante arbitrário no qual se enraíza um acontecimento, o sinthoma ou a maneira singular de cada um usufruir de Um-corpo. Em nossa prática, acreditamos que existe uma relação entre o sentido e o real por meio do sintoma. Se não fosse essa crença no sintoma, a operação analítica careceria de qualquer ancoragem legítima no real. A psicanálise se reduziria ao exercício de uma narratologia, inspirada numa posição nominalista ou pós-moderna no que se refere à relação entre o significante e o real. A prática psicanalítica é realista; seu realismo se ancora no fato de que as representações, os sentidos ou as verdades variam, mas o sintoma permanece — razão pela qual nós o consideramos, na nossa prática, como equivalente ao real. 
“Se há alguma coisa que eu sou, está claro que é que eu não sou nominalista. Quero dizer que não parto do seguinte, que o nome seja alguma coisa que se cola, assim, sobre o real. [...] Não se trata de ser realista no sentido em que se era na Idade Média, no sentido do realismo dos universais, pois se trata de levar em conta isto, que nosso discurso científico não encontra o real, senão na medida em que ele depende da função do semblante.” (LACAN, 1971-2006, p.28)

Proponho que a prática é da ordem do semblante, diferentemente da perspectiva da psicanálise como uma ciência cujo horizonte é o real sem sentido. Um semblante é um tratamento do real pelo simbólico, ele mistura razão e sensibilidade. Afirmar que a psicanálise é uma práxis não a diferencia propriamente da ciência. Práxis é um termo amplo que designa "uma ação realizada pelo homem (...) que o põe na condição de tratar o real pelo simbólico.” (LACAN, 1964/651985, p.14). O semblante precisa tocar o real, conectar-se com ele, mobilizá-lo, comovê-lo. Lacan, ao final de seu ensino, aspirava que a psicanálise fosse um discurso que não seria semblante, que tal como a ciência engendrasse efeitos no real. Esta aspiração, ao longo de seu ensino, é marcada por uma constante ambiguidade, justificada, talvez, pela necessidade de manter uma dicotomia entre ciência e prática. Como interpretar suas últimas declarações sobre este tema? No Seminário XXIV, L'insu que sait de l'une bévue s'aile à mourre, Lacan se manifesta sobre este tema conforme se segue:

“A psicanálise - eu o disse e eu o repeti recentemente — não é uma ciência. Ela não tem seu estatuto como ciência e não pode senão aguardá-lo, esperá-lo. Mas é um delírio do qual nós esperamos que ele porte uma ciência. É um delírio do qual esperamos que se torne científico. (...) Podemos aguardar muito tempo, eu digo porquê, simplesmente porque não há progresso e aquilo que esperamos não é forçosamente aquilo que recolhemos. É um delírio científico portanto, e esperamos que ele porte uma ciência mas, isso não significa que jamais a prática analítica portará esta ciência.” (LACAN, 11/01/1977, p.52)

Diferentemente deste voto ambíguo, em seu Seminário intitulado Le moment de conclure, a questão retorna da seguinte maneira:

"O que tenho a lhes dizer, é que a psicanálise é para ser levada a sério, apesar de que não é uma ciência. Não é mesmo uma ciência de jeito nenhum. Pois, o mais enfadonho, como mostrou superabundantemente o assim chamado Karl Popper, não é uma ciência porque é irrefutável. É uma prática." (LACAN, 15/11/1977, p.9) 
E o que seria uma ciência no último ensino de Lacan? Trata-se do campo no qual a representação se separa completamente do Gozo do Outro (JA). O Gozo do Outro está fora da linguagem, fora do simbólico. O Gozo do Outro é o impossível. Somente o campo onde nasce a ciência pode preenchê-lo. Esta pequena citação contribui para esclarecer um pouco esta tese:

“(...) só a partir do momento em que Galileu fez pequenas correspondências de letra a letra com uma barra de intervalo, por meio das quais definiu a velocidade como relação entre espaço e tempo, foi que se pode sair de tudo o que havia de intuitivo e travado na noção de esforço, para chegar ao primeiro resultado que era a gravitação." (LACAN, 1974, p.33)

Apenas a ideia de que o livro da natureza está escrito com caracteres matemáticos permite precisar que esse discurso - o científico - apresenta a dimensão do simbólico esvaziada do imaginário. “A ciência parte da letra. É por essa razão que deposito alguma esperança no fato de que se passando de toda representação, talvez cheguemos a ter dados mais satisfatórios sobre a vida." (LACAN, 1974/2011, p.33).

Na conferência publicada com o título de $A$ terceira, o real da psicanálise coincide em parte ou inteiramente com o da ciência: "Suponham que não houvesse nada de impossível no real — os cientistas fariam uma careta e nós também. Mas quanto caminho foi preciso percorrer para ver isso. Durante séculos acreditou-se que tudo era possível." (1974/2011, p.16). O real não é o mundo. Não há nenhuma esperança de alcançá-lo por meio da representação. O real não é o universal, não se pode dizer “todos são". Ele só é todo, no sentido de que cada um dos seus elementos é idêntico a si mesmo. As letras (S1) e o objeto (a) escrevem justamente esta identidade de si a si. O significante-unidade é fundamental, pois lalíngua precipita-se na letra, na escrita, na cifração que engendra o sintoma a partir de algo do real que não cessa de se escrever: a pré-maturação, o desamparo e a morte.

E o que seria a letra? É unicamente o que nos abre o acesso ao real. É apenas por meio dela que captamos o que haveria de mais vivo ou de mais morto na linguagem. A biologia lacaniana não é a mesma que a freudiana. Em A terceira ele se mostra surpreso com o fato de que algo de real, a própria vida, se estrutura como um nó. É também surpreendente, Lacan observa, que não exista na natureza (nem na anatomia, nem nas plantas trepadeiras) nenhuma imagem natural do nó. O DNA e a letra seriam homólogos em sua estrutura e igualmente estranhos ao campo da representação.

Foi no Seminário XX, Mais ainda, que Lacan estabeleceu essa homologia curiosa entre a letra e o gérmen, que nos dá a chave dessa relação entre a vida 
e a estrutura do nó. Ela repercute em outra clave a distinção que Freud efetuou entre o germoplasma e o somatoplasma. Para Freud (1914), o indivíduo seria atravessado pela divisão entre as pulsões de autoconservação — interessadas na sua sobrevivência - e as pulsões sexuais que veiculam o desejo imortal da espécie de crescer e se reproduzir, consagrando a vida do indivíduo à morte. Encontrei em Miller esta proposição que explicaria porque a letra é análoga ao gérmen: "Primeiramente porque sendo a letra aquilo que, do significante, se inscreve no corpo, ela é incorporada. (...) Em segundo lugar, essa letra não é o soma e, por último, a duração da letra se estende além da vida” (1999, p.45).

O DNA na biologia genética é a metáfora do real, assim como a cadeia borromeana é a metáfora do real no campo da psicanálise. Lacan propõe substituir a energética freudiana por esta nova metáfora, que não é uma ideia porque não é uma representação, é uma escrita que não se presta à imaginação. Por quê? Em primeiro lugar, porque Freud não teria fundado efetivamente uma energética. De acordo com Miller (2010), Lacan pensava que a ideia de neurônios e de passagens de energia enquanto verdade última do inconsciente, seria da ordem da imaginação.

Diferentemente de Freud, ele pretende forçar uma nova escrita com valor traumático, pois a metáfora da cadeia borromeana não seria uma ideia que floresce de modo espontâneo apenas devido ao que faz sentido, isto é, ao imaginário. Um novo tipo de ideia, destaca Miller (2010), que se assenta sobre a disjunção entre o simbólico e o imaginário, recordando a citação que se segue extraída do Seminário 23: "Eu inventei o que se escreve como real. Naturalmente, o real, não é suficiente escrevê-lo real. Muita gente o fez antes de mim. Mas este real, eu o escrevi sob a forma do nó borromeano, que não é um nó mas é uma cadeia que tem certas propriedades” (LACAN, 1975/76-2005, p.129-130).

Ou ainda, como sublinha Miller (2010, p.68): “(...) para que haja corte epistemológico, para que haja ciência, é preciso que o simbólico seja separado do imaginário." Mas, em contrapartida, é do corte com o imaginário que procedem as confusões do simbólico. O fato de não ter apoio no imaginário, introduz confusões e lapsos diversos no simbólico. Portanto, se supomos que o imaginário e o simbólico são disjuntos, torna-se necessário introduzir uma terceira dimensão, o real, para conectá-los:

"Na forma mínima sob a qual tracei esta cadeia, é preciso ao menos três elementos. O real, isto consiste em chamar um destes três de real. Estes três elementos tal como eles estão enodados, em realidade encadeados, fazem metáfora. Não é nada mais do que metáfora da cadeia." (LACAN, 1975/76-2005, p.129-130) 
De que real se trata no último ensino de Lacan? É o que se aproxima do que Freud define como reminiscência. Diferentemente da rememoração, trata-se de uma impressão no sistema nervoso, ou, ao que no ensino de Lacan é da ordem da letra. A rememoração consistiria na constituição de redes de memória que se trançam. Lacan procura estabelecer a memória em bases novas, mediante alguma coisa que se encadeia ao invés de se trançar. De um lado Lacan faz a crítica da ideia de que o símbolo já estaria pré-formado no imaginário. A origem símbolo é o significante e não a imagem. De outro, critica a energética freudiana por estabelecer uma relação direta entre os neurônios investidos com a energia psíquica e o inconsciente, o que anularia a dimensão do real. A energética freudiana estaria baseada na suposição de que o imaginário está no simbólico e o simbólico no imaginário — é isso que funciona e que constitui a realidade:

“Em contrapartida, para Lacan, essa relação entre o simbólico e o imaginário é condicionada por um termo suplementar: o real, sem o qual não se tem nem realidade, nem funcionamento. É nesse sentido que ele pode dizer meu real condiciona a realidade." (MILLER, 2010, p.71)

Ou, dizendo de outro modo: para que um dizer seja ouvido, não basta a emissão fonadora (fala) que mobiliza o corpo - é preciso que o auditor escute (ouça). A realidade é precária, pois existe entre um e outro um abismo. Para efetuar a fusão entre imaginário e simbólico, é preciso um acontecimento real. O inconsciente freudiano, diferentemente, seria por completo redutível a um saber falado que, no mínimo, pode ser interpretado. O S1, ao representar o sujeito verdadeiramente, isto é, para um S2, implica que o dizer é conforme a realidade. A realidade é o que funciona verdadeiramente. Vejamos porque Lacan pretende que a instância do saber renovada por Freud sob a forma do inconsciente não supõe obrigatoriamente de modo algum o real do qual ele se serve.

A introdução desta terceira dimensão, a do real, implica supor que a língua é criada a cada ato de fala — logo, não existe inconsciente transindividual, nem inconsciente de uma língua. O inconsciente é sempre particular. E, neste sentido, o inconsciente é real. O sentido que vale para um, não vale necessariamente para os outros. Esta é a razão pela qual Lacan dirá que: "O que constitui em si uma energética é que é preciso achar um truque para obter a constante." (LACAN, 1975/76-2007, p.130). O truque conveniente, aquele que funciona, que obtém êxito, é o que chamamos de realidade: “(...) eu penso na medida em que meu pensamento é mais que um sintoma - que o falo possa ser suporte suficiente para o que Freud concebia como energético." (Idem, p.134) 
Aliás, a realidade não é o termo mais essencial para se contrapor ao real. É mais importante diferenciar o real com o qual o imaginário e o simbólico estão enlaçados no nó borromeano, isto é, no sinthoma, daquilo que da realidade serve para estabelecer a ciência. E finalmente, o real é um órgão que não tem nada a ver com o órgão carnal. O inconsciente freudiano não deixa de ser referido ao corpo. Indiscutivelmente o que Freud entendia por pulsão remete à materialidade da energética no psiquismo:

“... conceito situado na fronteira entre o mental e o somático, como representante psíquico dos estímulos que se originam dentro do organismo e alcançam a mente, como uma medida da exigência feita à mente no sentido de trabalhar em consequência de sua ligação com o corpo.” (FREUD, 1915-1974, p.142)

Lacan, diferentemente, argumenta que "a função do real deve ser distinguida dele.” A menos que o inconsciente seja real. Não é a mesma coisa supor que existe uma constante que suporta a mediação entre os significantes — por exemplo, Deus, o Nome do Pai, o próximo (Nebenmesch), o Outro da linguagem, ou o princípio do prazer/realidade - e advogar que não há Outro do Outro, que o Outro não existe, que o real é um furo no simbólico, razão pela qual é sem lei. No primeiro caso, trata-se da psicanálise como uma práxis, situada no âmbito da realidade, no ponto em que existe funcionamento e êxito. É disso que se trata quando Lacan definia a práxis como: "tratar o real pelo simbólico". O que é a mesma coisa que supor que o inconsciente é transferencial. É supor que aquele que fala endereça seu dizer a alguém. Mas, se cada ato de fala, em princípio, não quer dizer nada para ninguém, não se estaria mais sob a hegemonia da transferência. Entretanto, se um ato de fala alcança tornar-se um dizer, não poderá deixar de se submeter às regras da lógica — ao princípio da não contradição — que poderão confirmá-lo ou desdizê-lo.

O último ensino de Lacan traz considerações bastante embaraçosas sobre o pensamento de Freud. Os cursos de orientação lacaniana de Miller são muitas vezes indispensáveis ao trabalho de construção da lógica do pensamento de Lacan neste período do seu ensino - em particular, no que se refere ao tema da diferença entre a psicanálise no sentido absoluto e sua prática. Freud estabeleceu o método psicanalítico como um instrumento de pesquisa do inconsciente. Considerava-se muito mais inclinado à pesquisa do que afeiçoado aos objetivos terapêuticos. Não se pode imputar à Freud a ideia de que a psicanálise tem a ambição de reconduzir à realidade, ao funcionamento, ao êxito psicoterapêutico. Nada menos freudiano. Sua formulação de um princípio mais além do princípio do prazer assegura — e sobre isto Freud parafraseia Göethe — que não há nada, nem no céu, nem na terra, preparado para que o homem seja feliz. 
O estatuto da psicanálise foi definido por Freud por meio de um paradoxo. A invenção freudiana, embora faça parte da Weltanshäuung da ciência, teria introduzido nela um objeto que questiona os poderes da racionalidade científica: a realidade psíquica. O sonho, o inconsciente e o sintoma são ficções que se alimentam do desejo de um pai. Nutrem-se do sentido religioso, afastando-se do real sem sentido que anima a pesquisa científica. O desamparo é a fonte desta grande aspiração libidinal e moral da espécie humana. O pai é uma ficção verdadeira, mas a verdade, para Freud, não equivale ao real. O real — no campo da teoria psicanalítica - é o circuito que a pulsão descreve repetidamente buscando o objeto, sentido evanescente, que se anuncia, não permanece e escapa. Ao real da psicanálise freudiana é impossível atribuir um sentido. A ideia de que a pulsão de morte visa retornar ao inanimado é tão somente uma metáfora do real. Todo o percurso freudiano começou por estabelecer que a grande verdade revelada pelo inconsciente — a do pai sedutor — não passa de uma fantasia, de primeira mentira (proton pseudos) histérica, um sintoma. Não temos aí, justamente, o princípio de uma duplicidade de estatuto entre a psicanálise, como ciência da pulsão, e de sua prática, enquanto estruturada pelas ficções do inconsciente que sustentam os sintomas? Não é o sintoma o único real no qual o psicanalista, desde Freud até Lacan, acredita?

Não se pode dizer que as verdadeiras ciências se distinguem da psicanálise porque abolem toda a dimensão da crença. Porque não seria a ciência, também ela, uma ficção? Por mais identificado com a razão universal que um ser humano aspire vir a ser, não poderá eliminar em sua subjetividade os restos, as marcas, as evidências e a pressão do profundo desamparo que é a causa de seus desejos infantis. E é essa também a fonte da religião, que engendra a crença em um pai protetor. A ciência prolonga esta necessidade de superar o desamparo por outros meios, apostando nos poderes da razão. Acreditar na razão não seria equivalente a acreditar em Deus? Na ciência, a crença na natureza toma o lugar da crença em Deus. Quando a psicanálise reduz o Nome do pai ao inconsciente, no mesmo golpe ela destitui a crença na universalidade e na neutralidade da razão. Lacan reduz a ciência a uma futilidade sem nenhum peso na vida, embora ela tenha resultados impressionantes, como, por exemplo, a televisão:

\footnotetext{
"Para que o imaginário se exfolie, é preciso somente reduzi-lo ao fantasma. O importante é que a ciência, ela mesma, é somente um fantasma e que a ideia de um despertar é propriamente impossível." (15/11/1977a, p.15)
} 


\section{CIÊNCIA E DISCURSO: LACAN VERSUS LACAN?}

Se não existe saber que não seja marcado pelo pecado de origem da fé e, se deste pecado original nem a ciência escapa, haveria alguma diferença a conservar entre ciência e discurso? Para formalizar a questão, parto de um aforismo de Lacan que aparenta contradizer minha tese. No Seminário 16, intitulado De um Outro ao outro, o autor afirma que: "a essência da teoria psicanalítica é um discurso sem palavras.” (1968/69-2006, p.11). Não haveria nenhuma distinção a fazer entre um matema - que é uma redução da verdade à estrutura esvaziada de sentido - e um discurso sem palavras. A definição lacaniana de discurso, justamente, não prescinde de palavras? Se um discurso não precisa de palavras, em que ele se distingue de uma fórmula científica?

Devemos à conferência Qu'est-ce qu'un auteur?, proferida por Michel Foucault (1969), a tese de que a psicanálise não é uma ciência. De acordo com Foucault, Freud e Marx teriam sido instauradores de novas discursividades, distintas de outra prática discursiva, a da ciência. Uma verdade estabelecida, que pode ser muitas vezes demonstrada no campo da ciência, não precisa garantir sua autenticidade referindo-se ao indivíduo que a estabeleceu. Torna-se, por assim dizer, anônima. A física de Newton, de Galileu ou de Einstein não precisa retornar ao ato de fundação deste campo do conhecimento para reconhecer a validade de uma proposição. De modo diverso, ao ato de instauração da psicanálise como uma discursividade seria preciso retornar muitas vezes, para estabelecer o valor de verdade dos avanços e progressos desse campo do saber.

Poderíamos argumentar, contra a tese de Foucault, que a física de Galileu, a mecânica de Newton, a teoria da relatividade de Einstein ou a mecânica quântica de Bohr são também discursos que não se desprendem jamais de suas origens, do Nome do Pai, do nome próprio de seu inventor. A psicanálise não é a linguística, ainda que não se possa desvencilhá-la da importância do nome de Ferdinand de Saussure, mas o saber inconsciente estrutura-se como a linguagem. O que é que faz da linguística uma ciência? É o que Lacan explica nas Conferências de Saint-Anne:

“Eu me servi disso porque era realmente necessário para introduzir o que concerne ao discurso analítico, servi-me sem escrúpulo das trilhas que teriam podido se exaltar cedo demais e fazer vocês retornarem à lama cotidiana, eu lembrei que não se afirmou coisa alguma digna desse título linguístico como ciência, não se afirmou coisa alguma que pareça ter a língua, nem mesmo a fala, como objeto, não se afirmou senão na condição de jurarem entre si, entre linguistas, de nunca, nunca mais - porque não fizemos outra coisa durante séculos - nunca mais, nem de longe, fazer alusão à origem da linguagem" (LACAN, 1971-72a, aula de 3/2/1972, p.61) 
Quando Foucault se referia à psicanálise como uma discursividade, muito provavelmente tomava como uma condição essencial ao seu progresso a estratégia lacaniana de refundar a psicanálise por meio da retórica épica do resgate das origens. O famoso retorno a Freud, foi, na verdade uma releitura da obra freudiana à luz da função e do campo da fala e da linguagem. Lacan defendia a necessidade de voltar às origens, argumentando que os pós-freudianos desviaramse dos princípios fundamentais da ciência que Freud inventou. Foi este gesto que levou Foucault a supor que a psicanálise não seria uma ciência, não gozaria do anonimato de uma verdade que pode ser muitas vezes demonstrada e que dependeria do gesto de retornar às origens, ao texto, à citação, para refundar-se.

Acredito que não devemos confundir a psicanálise no sentido absoluto com o discurso analítico. A próxima citação sublinha o que Lacan entende por discurso: é uma estrutura que se funda na função de S1 (significante mestre), que, articulado a um S2 (o saber) constitui o sujeito ( \$, dividido entre dois significantes: S1-S2), operação que produz o objeto a como um resto ou um excesso (mais de gozar). Essa estrutura ergue-se sobre um pano de fundo, comum a qualquer ciência, que é o real impossível. Todo discurso é semblante. Todo discurso é uma arquitetura que pretende abordar o real pela via do simbólico. Todo discurso aspira agir sobre o real e produzir efeitos:

"O que eu gostaria de dizer mais livremente é que fazendo alusão, nesse escrito, ao discurso analítico, sobre o qual eu me encontro em posição de abrir o caminho, é evidentemente na medida em que o considero como constituindo, pelo menos potencialmente, essa espécie de estrutura que designo com o termo discurso, isto é, aquilo pelo qual, pelo efeito puro e simples da linguagem, se precipita num laço social. Isso foi percebido sem necessidade da psicanálise. É exatamente o que chamamos, na linguagem corrente, ideologia." (LACAN, 1971-72a, aula de 4/5/1972, p.96)

Como entender essa equivalência entre tudo isso que se precipita como efeito puro da linguagem, o discurso que é uma estrutura, o laço social e a ideologia? Seria alguma coisa próxima da leitura de Althusser (1970) sobre a ideologia na filosofia de Marx? De acordo com este autor, Marx concebe a estrutura da sociedade em dois níveis ou instâncias, articulados por uma determinação específica: a infraestrutura econômica e a superestrutura. Esta última, por sua vez, comporta outras duas instâncias: jurídico-políticas (Estado e Direito) e ideológicas (moral, religião, política). A superestrutura serve à reprodução das condições de produção que se relaciona com a atividade do Estado e de seus aparelhos ideológicos. O objetivo comum é assegurar a submissão da força de trabalho à ordem estabelecida. Os aparelhos ideológicos estão diretamente implicados na 
manutenção do laço social (escola, igreja, família, direito, política, cultura). Por isso, a ideologia dominada pelas pressões do interesse não conhece - reconhece. Serve às finalidades prático-sociais, e não à produção de conhecimento como faz a ciência. O objetivo da ideologia é forjar uma visão de mundo que integra elementos simbólicos disjuntos e até contraditórios.

A psicanálise enquanto um discurso, o discurso analítico, faria parte dos aparelhos ideológicos do Estado? Serviria à reprodução dos laços sociais estabelecidos por meio desta forma histórica chamada família? Não poderíamos aproximá-la da noção foucaultiana de dispositivo? Enfim, como propunha Foucault (1977), a psicanálise seria apenas uma das tecnologias perversas e polimorfas do poder sobre os corpos e as sexualidades? Afinal, a estrutura do discurso é um semblante, reúne razão e sensibilidade. De um lado serve para excluir o real impossível, isto é, o gozo ou a pulsão de morte. De outro, reúne o sintoma (S1-S2) e o fantasma $(\$<>a)$ numa fórmula de dois andares. Por analogia ao aparelho conceitual marxista, podemos sonhar que o sintoma é a superestrutura, enquanto que o fantasma é sua infraestrutura libidinal. A estrutura do discurso é uma formalização das relações edipianas. Recordo a correspondência de cada uma dessas letras com um dos termos em jogo no Complexo de Édipo: S1 (Nome do Pai), S2 (saber/desejo da mãe), \$ (sujeito dividido) e objeto a (mais de gozar). De acordo com Lacan, este discurso é uma máquina que não se reduz a recalcar (Urverdräng) o gozo, rejeitando-o ao campo do impossível. Trata-se também de uma máquina produtiva na qual o gozo é recuperado sob a forma do lucro, da mais-valia (mais de gozar). Não temos aqui uma equivalência entre a definição lacaniana de discurso e a definição althusseriana de aparelho? Não se trataria também da mesma coisa que Foucault chamou de dispositivo?

\section{CIÊNCIA, REAL, PULSÃO DE MORTE VERSUS IDEOLOGIA, NOME DO PAI, INCONSCIENTE}

Se esta hipótese vale alguma coisa, somos conduzidos a levantar duas questões: ou a ciência é um discurso entre outros (muito embora Lacan não tenha designado nenhum dos discursos como discurso da ciência) ou o discurso analítico é uma prática — não sendo, portanto, uma ciência. Isto nos reconduziria à hipótese inicial de que haveria uma dicotomia interior ao campo da psicanálise. De um lado, a psicanálise no sentido absoluto é uma ciência que aborda o real tal como a lógica, excluindo dele todo o sentido. De outro, ela é uma prática que consiste em interpretar o sintoma, que é uma exceção à regra de que no real não há sentido. O sintoma, enquanto conjunção entre o real e o sentido, indica-nos que o real do qual tratamos em nossa prática não é o mesmo real (uma existência expurgada de sentido) que é o horizonte da psicanálise no sentido absoluto. 
Muitas vezes abordei o tema da dualidade, ao final da análise, entre a dimensão que é terminável e aquela que se mostra interminável. Freud nomeia o impasse analítico por meio do rochedo da castração. Homens e mulheres defendem-se da feminilidade (Weiblichkeit) por meio da cicatriz do complexo de castração. Para Freud, a sexuação conduz à angústia de castração nos homens e à reivindicação (Penisneid) do falo nas mulheres. As duas atitudes são defesas contra a feminilidade. O termo feminilidade equivale ao real impossível em Lacan. Lembrando, entretanto, que:

“A pulsão de morte é o real na medida em que ele só pode ser pensado como impossível. Quer dizer que, sempre que ele mostra o nariz, ele é impensável. Abordar este impossível não poderia constituir uma esperança, posto que é impensável, é a morte - e o fato de a morte não poder ser pensada é o fundamento do real." (LACAN, 1975/76-2011, p.121)

O que nos traz de volta à sua aspiração de que a cadeia borromeana (ou o nó borromeano) seja uma escrita que funcione como metáfora do real. Ela seria expurgada de sentido. Ela não seria uma ideia, pois não se trata de uma representação. Ela seria uma escrita equivalente à morte e à vida enquanto irrepresentáveis. Seria equivalente ainda à feminilidade (horizonte inatingível do processo analítico) e à pulsão de morte. Esta última, todavia, não é uma vontade obscura de destruição ou de retorno ao inanimado como as metáforas energéticas freudianas propõem. Ela é relativa ao Outro que não existe, mais além da hipótese do inconsciente e da suposição do Nome do Pai, isto é, de Deus:

"A hipótese do inconsciente, sublinha Freud, só pode se manter na suposição do Nome do Pai. É certo que supor o Nome do Pai é Deus. Por isso a psicanálise, ao ser bem sucedida, prova que podemos prescindir do Nome do Pai. Podemos sobretudo prescindir com a condição de nos servirmos dele." (LACAN, 1975/762011, p.133)

É discutível que a prática analítica possa conduzir a uma existência expurgada de sentido. Até porque, isso redundaria em tornar possível o impossível. Nesta medida, a psicanálise fracassa em atingir seu horizonte absoluto. Será por essa razão que Lacan se mostra tão resistente em admiti-la ao campo da ciência? Se é esse o caso, porque essa ambição em produzir uma escrita que equivalha ao real? Será que se trata apenas de sua resposta sintomática a Freud?

\footnotetext{
"Falo do real como impossível na medida em que creio justamente que o real enfim creio, se é esse meu sintoma, digam-me —, é preciso dizê-lo bem, o real é sem
} 
lei. O verdadeiro real implica a ausência de lei. O real não tem ordem.” (LACAN, 1975/76-2011, p.133)

A invenção lacaniana do real — sua reação ao inconsciente, ou sua resposta sintomática à elucubração freudiana — é definida por ele como o ato de elevar ao grau de simbolismo seu próprio sinthoma. Gesto que, tal como o do cientista no campo da ciência, consiste em esvaziar ao máximo aquilo que o sintoma possa ter de reprodução ideológica dos discursos e laços sociais fundados na tradição, convidando cada psicanalista a inventar a psicanálise novamente.

Recebido em 15/8/2013. Aprovado em 26/9/2013.

\section{REFERÊNCIAS}

ALTHUSSER, L. (1970). Ideologia e os aparelhos ideológicos do Estado. Lisboa: Editorial Presença.

FOUCAULT, M. (1969 /1983). Qu'est-ce qu'um auteur? Conferência pronunciada na Sociedade Francesa de Filosofia em 22 de janeiro de 1969, Revista Littoral, Paris, 9 de junho.

. (1977). História da sexualidade volume I - A vontade de saber. Rio de Janeiro: Graal.

FREUD, S. (1974 e 1976) Edição standard das obras completas de Sigmund Freud. Rio de Janeiro: Imago.

[1932 (1933) 1976] “A questão de uma Weltanschauung”, v.XXII, p.193222.

[(1915)1974]. “Os instintos e suas vicissitudes”, v.XIV, p.129-164.

LACAN, J. (1965/66-2011). “La science et la verité”, in Ecrits. Paris: Seuil.

(1964/65-1985). O Seminário Livro XI, Os quatro conceitos fundamentais. Rio de Janeiro: Zahar Editores. - (1971/72a). O saber do psicanalista. Publicação do Centro de Estudos Freudianos de Recife, s/d. (1971/72b- 2011). Le Seminaire. Livre XIX: ou pire. Paris: Seuil.

(1974/75). Le Seminaire XXII: R.S.I. Paris: Éditions de La Association Freudienne Internationale, s/d.

. (1974-2011). La Troisème. Révue de la Cause Freudienne, Nouvelle Revue de Psychanalyse 79, Navarin Editeur, p.11-33.

(1974-2011). A Terceira. Opção Lacaniana, Revista Brasileira Internacional de Psicanálise, 62, dez/2011, p.11-36.

. (1975/76- 2005). Le Seminaire. Livre XXIII: le sinthome, Paris: Seuil. (1975-76- 2011). O Seminário Livro 23 O sintoma. Rio de Janeiro:

Zahar Editores. 
(1976-77). Le Seminaire. Livre XXIV: L'insu que sait de l'une bévue s'aile à mourre. Paris: Éditions de La Association Freudienne Internationale, s/d.

(1977-78). Le Seminaire XXV: le moment de conclure. Paris: Éditions de La Association Freudienne Internationale, s/d.

MILLER, J.-A. (1999). Elementos de biologia lacaniana, Belo Horizonte: EBP. . (2010). Perspectivas do Seminário 23 de Lacan: O sinthoma. Rio de Janeiro: Zahar Editores.

(2011). Perspectivas dos escritos e dos outros escritos de Lacan: entre desejo e gozo, Rio de Janeiro: Zahar Editores.

(2012). O real no século XXI. Opção Lacaniana Revista Brasileira Internacional de Psicanálise, 63, jun, p.11-20.

(2013). O real é sem lei. Opção Lacaniana Revista Brasileira Internacional de Psicanálise, 65, abril/2013, p.9-24.

\section{Obras consultadas}

COELHO DOS SANTOS, T. (2009). Semblante e discurso: estrutura e verdade na ciência e na psicanálise, Latusa Revista da Escola Brasileira de Psicanálise, 14, p.39-52.

. (2011). A dimensão real da inserção na ordem simbólica. aSEPHallus Revista de Orientação Lacaniana (Online), VI (11), nov./2010, abr., 1-17. Disponível em www.isepol.com/asephallus.

(2011). "A materialidade da letra e o realismo da estrutura na psicanálise de orientação lacaniana”, in LO BIANCO, A. C. (Org.) A materialidade da psicanálise. Rio de Janeiro: Contracapa, p.81-100.

(2012). "Existe uma nova doutrina da ciência na psicanálise de orientação lacaniana?”, in ___ . MARTELLO, A.; SANTIAGO, J. (Orgs.) De que real se trata na clínica psicanalítica? Psicanálise, ciência e discursos da ciência. Rio de Janeiro: Cia de Freud, p.35-62.

. (2012). O real sem sentido nas ciências em geral e na psicanálise em particular. aSEPHallus Revista de Orientação Lacaniana, VII (13), nov/2011, abr,.12-29. Disponível em www.isepol.com/asephallus.

\& LOPES, R. G. (2013). Psicanálise, ciência e discurso. Rio de Janeiro: Cia. de Freud.

COTTET, S. (2012). Um bien dire épistemologique. Du concept dans la clinique, La Cause du Désir, Nouvelle Revue de Psychanalyse, 80, mars, Navarin Editeur, p.16-22.

(2013). Em ligne avec Serge Cottet, in La science est votre verité La Cause du Désir, Nouvelle Revue de Psychanalyse, 84, mai, Navarin Editeur, p.12-22.

LICITRA-ROSA, C. (2009). Il n'ya d’analyste qu'à ce que ce désir [du savoir cientifique] lui vienne. Lettre mensuelle, 280, Paris: École de la Cause Freudienne, 16-19.

Tania Coelho dos Santos

taniacs@openlink.com.br 